JURNAL Midwifery Update (MU)

http://jurnalmu.poltekkes-mataram.ac.id/index.php/jurnalmu

e-ISSN: 2684-8511 (Online)

\title{
INTENSITAS NYERI PINGGANG DAN PINGGUL PADA IBU HAMIL YANG MELAKSANAKAN YOGA PRENATAL DI KOTA DENPASAR
}

\author{
Ni Made Dwi Purnamayanti ${ }^{1}$,Gusti Ayu Eka Utarini ${ }^{2}$ \\ 1,2 Jurusan Kebidanan Poltekkes Kemenkes Denpasar
}

\begin{abstract}
Abstrak
Nyeri pinggang dan panggul merupakan keluhan yang umum dirasakan oleh wanita hamil terutama pada akhir kehamilan. Olah raga termasuk yoga prenatal merupakan strategi yang efektif dan disarankan untuk mengatasi nyeri pinggang dan panggul. Penelitian ini bertujuan untuk mendapatkan gambaran intensitas nyeri pinggang dan panggul pada ibu hamil trimester III yang melaksanakan yoga prenatal di Kota Denpasar. Penelitian ini merupakan penelitian deskriptif observasional dengan pendekatan cross sectional terhadap 96 ibu hamil trimester III yang melaksanakan yoga prenatal di kota Denpasar. Didapatkan hasil rerata intensitas nyeri pinggang dan panggul yang dirasakan adalah 1.88 ( $\mathrm{SD} \pm 2.202)$. Sebagian besar responden (41.7\%) merasakan nyeri pada area tulang belakang disekitar lumbal hingga diatas sacrum. Intensitas nyeri pinggang dan pelvis pada ibu hamil trimester III di Kota Denpasar yang melaksanakan yoga prenatal tergolong nyeri intensitas ringan.
\end{abstract}

Kata Kunci: yoga prenatal; nyeri pinggang ; kehamilan

\section{PREGNANCY-RELATED LUMBOPELVIC PAIN AMONG PREGNANT WOMAN WHO PERFORM YOGA PRENATAL IN DENPASAR}

\begin{abstract}
Lumbopelvic pain are common complaints felt by pregnant women. Exercise, including prenatal yoga, is an effective strategy and is recommended for treating pregnancy-related lumbopelvic pain. The purpose of the syudi is to know the intensity of pregnancy-related lumbopelvic painamong woman who performe prenatal yoga in Denpasar. This study was an observational descriptive study with a cross sectional approach. The subjeck study was 96 third trimester pregnant women who performed prenatal yoga in Denpasar. The mean pain intensity was $1.88(\mathrm{SD} \pm 2.202)$. Most respondents (41.7\%) felt pain in the spinal area around the lumbar to above the sacrum. The intensity of pregnancy-related lumbopelvic pain among third trimester pregnant women in Denpasar who performe prenatal yoga is mild pain.
\end{abstract}

Keyword: prenatal yoga ; hip pain ; pregnancy 


\section{Pendahuluan}

Nyeri pinggang dan panggul adalah keluhan umum ibu hamil, umumnya dirasakan sebagai ketidaknyamanan aksial atau para-sagital di daerah pinggang bawah hinggan ke bokong bahkan paha. 1,2 Banyak istilah yang dipergunakan untuk menggambarkan permasalah musculoskeletal pada pinggang dan pelvis pada kehamilan. Istilah sering dipakai adalah pregnancy-related lumbopelvic pain, yang kemudian dibagi menjadi dua terminology lagi yaitu pregnancy-relatel pelvic gridle pain (PPP) untuk menggambarkan nyeri terkait permasalahan musculoskeletal pada daerah pelvis dan pregnancy-related low back pain (PLBP) untuk menggambarkan nyeri daerah lumbal ${ }^{17}$.

Nyeri ini disebabkan perubahan fisiologis pada ibu hamil, dimana pusat gravitasi bergerak maju karena peningkatan masa perut dan payudara yang menghasilkan lordosis lumbalis serta ketegangan pada otot paraspinal.Kompresi pembuluh darah besar oleh uterus gravid mengurangi aliran darah tulang belakang dan dapat menyebabkan nyeri punggung bawah, terutama pada paruh terakhir kehamilan. Retensi air yang disebabkan oleh stimulasi progesteron dan kelonggaran ligamen oleh hormone relaxin membuat tulang belakang dan sendi panggul kurang stabil dan karenanya lebih rentan terhadap stres dan rasa sakit ${ }^{6}$.

Penelitian terkait nyeri pinggang dan panggul pada kehamilan telah dilakukan diseluruh dunia, prevalensi yang dilaporkan bervariasi dari 45,3\% hingga 84,1\%. ${ }^{9,13,7,17}$ Penelitian di Indonesia juga menunjukkan prevalensi nyeri pinggang bawah pada kehamilan yang cukup tinggi. Di Rumah Sakit KH. Abdurrahman Syamsuri, Jawa Timur pada tahun 2015 prevalensi nyeri pinggang pada ibu hamil dilaporkan sebesar $54,5 \%{ }^{8}$. Ini menunjukkan bahwa keluhan nyeri pinggang bawah selama kehamilan dirasakan sebagian besar ibu hamil diseluruh dunia termasuk di Indonesia.

Nyeri pinggang memberikan banyak dampak negatif bagi wanita hamil ${ }^{4}$. Mereka mengalami kesulitan dalam menjalankan aktivitas sehari-hari seperti berdiri, duduk, berpindah tempat atau posisi, mengangkat atau memindahkan barang/benda disekitar. Terdapat beberapa bukti kerugian sosial ekonomi terutama sebagai akibat dari ketidakhadiran di tempat kerja ${ }^{10}$.

Therapy olah raga merupakan strategi yang efektif dan disarankan untuk mengatasi nyeri pinggang ${ }^{11}$. Bentuk-bentuk olah raga yang disarankan dapat berupa latihan kebugaran fisik umum atau latihan aerobik, hingga penguatan otot, berbagai jenis fleksibilitas, latihan peregangan termasuk yoga ${ }^{11}$.

Yoga merupakan bentuk latihan pikiran dan tubuh yang meliputi sistem latihan peregangan dan postur (asana) yang dikombinasikan dengan latihan pernapasan dalam (pranayama) dan meditasi ${ }^{3}$. Yoga adalah latihan dengan gerak perlahan, disengaja, dan mudah dimodifikasi sehingga menjadikannya latihan yang cocok untuk wanita hamil.Prenatal yoga di Indonesia diatur dalam Peraturan Pemerintah Republik Indonesia nomor 103 tahun 2014 tentang Pelayanan Kesehatan Tradisional.Dalam pelaksanaannya yoga prenatal dapat dilakukan terintegrasi dengan pelayanan kesehatan di fasilitas kesehatan.Yoga prenatal di Kota Denpasar dikembangkan sebagai kegiatan promotif dengan tujuan meningkatkan derajat kesehatan termasuk mengurangi keluhan nyeri pinggang dan panggul. 
Belum banyak penelitian yang dilakukan terkait keluhan nyeri pinggang dan pelvis pada kelompok ibu hamil yang melakukan yoga prenatal khususnya di Kota Denpasar.Penelitian ini bertujuan untuk mendapatkan gambaran intensitas nyeri pinggang dan panggul pada ibu hamil trimester III yang melaksanakan yoga prenatal di Kota Denpasar.

\section{Metode}

Penelitian ini merupakan penelitian deskriptif observasional dengan pendekatan cross sectional. Penelitian dilaksanakan di 4 puskesmas di Kota Denpasar yang dipilih secara acak sederhana.Sampel adalah ibu hamil diwilayah kerja puskesmas yang melaksanakan yoga prenatal berjumlah 96 orang.Kuesioner diberikan kepada responden dan intensitas nyeri dinilai dengan numeric pain rating scale. Data dianalisa secara deskriptif. Penelitian ini telah mendapatkan persetujuan dari Komisi Etik Penelitian Kesehatan Poltekkes Denpasar.

\section{Hasil dan Pembahasan}

Karaketristik subyek penelitian pada penelitian ini disajikan dalam table berikut. Tabel 1.Karakteristik Subyek Penelitian

\begin{tabular}{|c|c|c|}
\hline Karakteristik & Jumlah & $\begin{array}{c}\text { Prosentase } \\
(\mathbf{( \% )})\end{array}$ \\
\hline \multicolumn{3}{|l|}{ 1. Umur } \\
\hline$<20$ tahun & 4 & 4.2 \\
\hline 20-25 tahun & 25 & 26.0 \\
\hline$>25-30$ tahun & 43 & 44.8 \\
\hline$>30-35$ tahun & 21 & 21.9 \\
\hline$>35$ tahun & 3 & 3.1 \\
\hline \multicolumn{3}{|l|}{ 2. Gravida } \\
\hline Pertama & 48 & 50.0 \\
\hline Kedua & 32 & 33.3 \\
\hline Ketiga & 15 & 15.6 \\
\hline Keempat & 1 & 1.0 \\
\hline
\end{tabular}

Data diatas menunjukkan ibu-ibu yang melaksanakan yoga prenatal umumnya dalam rentang usia 20-35 tahun dan terbanyak pada usia 25-30 tahun (44.8\%). Sebagian besar merupakan kehamilan pertama (50\%).

Karakteristik ibu hamil yang mengikuti yoga prenatal di Kota Denpasar menunjukkan karakteristik kemapanan. Dari segi umur ibu hamil tergolong dalam usia reproduksi sehat dan terbanyak dalam rentang usia 25-30 tahun. Pada usia ini wanita dalam masa puncak kesuburan dan dalam kondisi ideal untuk bereproduksi.

Ibu hamil yang mengikuti yoga prenatal terbanyak merupakan kehamilan pertama. Hasil ini serupa dengan penelitian tentang antepartum gentle yoga di Yogyakarta ${ }^{15}$ yang menunjukkan sebagian besar $(79,4 \%)$ ibu hamil yang mengikuti kelas yoga adalah ibu hamil pertama. Hal ini mungkin terkait dengan ketersediaan waktu yang dimiliki oleh ibu hamil.Pada ibu hamil pertama belum disibukkan dengan tanggungjawab mengasuh anak, sehingga mempunyai lebih banyak waktu untuk mengikuti kelas yoga. Hasil ini berbeda 
dengan penelitian yang dilaksanakan di Australia ${ }^{3}$. yang menunjukkan ibu hamil terbanyak yang melaksanakan yoga adalah pada kehamilan kedua dan ketiga, yang tampaknya dipengaruhi perbedaan sosio-kultural tempat penelitian yang dilakukan.

Intensitas nyeri pinggang yang dirasakan oleh kelompok ibu hamil yang melaksanakan yoga prenatal di Kota Denpasar dapat dilihat pada table berikut.

Table 2. Intensitas Nyeri Pinggang dan Pelvis pada Ibu Hamil Trimester III yang Melaksanakan Yoga Prenatal di Kota Denpasar

\begin{tabular}{lccccc}
\hline \multicolumn{1}{c}{ Variable } & $\mathrm{n}$ & Mean & Range & SD & Median \\
\hline $\begin{array}{l}\text { Intensitas nyeri pinggang } \\
\text { dan panggul }\end{array}$ & 96 & 1.88 & $0-8$ & 2.202 & 1.00 \\
\hline
\end{tabular}

Table 2 menunjukkan rerata intensitas nyeri pinggang yang dirasakan oleh kelompok ibu hamil yang mengikuti yoga prenatal adalah $1.88(\mathrm{SD} \pm 2.202)$, intensitas minimum yang dirasakan adalah 0 dan intensitas maksimum yang dirasakan adalah 8 . Pengukuran ini menggunkan numeric rating pain scale dari skala 0 sampai dengan 10.Pengukuran menggunkaan numeric rating pain scale dari skala 0 sampai dengan 10, 0 diartikan tidak ada rasa nyeri dan 10 diartikan sebagai nyeri terkuat yang bisa dibanyangkan.Pada penelitian ini 44 orang $(45.8 \%)$ menyatakan tidak merasakan nyeri pinggang dan pelvis dengan intensitas 0 dan 52 orang (54.2\%) menyatakan adanya rasa nyeri dengan intensitas $\geq 1$.

Tabel 3. Lokasi Nyeri Pinggang dan Pelvis pada Ibu Hamil Trimester III yang Melaksanakan Yoga Prenatal di Kota Denpasar

\begin{tabular}{lcc}
\hline \multicolumn{1}{c}{ Lokasi Nyeri } & Jumlah & $\%$ \\
\hline $\begin{array}{l}\text { 1. Tidak ada rasa nyeri } \\
\text { 2. Ada rasa nyeri } \\
\text { a. Area tulang belakang disekitar lumbal hingga di } \\
\text { atas sakrum }\end{array}$ & 44 & 45.8 \\
$\begin{array}{l}\text { b. Area krista iliaka posterior dan lipatan gluteal } \\
\text { hingga ke paha posterolateral }\end{array}$ & 40 & 41.7 \\
c. Keduanya & 7 & 7.3 \\
\hline$\quad$ Jumlah & 5 & 5.2 \\
\hline
\end{tabular}

Tabel diatas menunjukkan sebagian besar (41.7\%) ibu hamil merasakan nyeri pada area tulang belakang disekitar lumbal hingga diatas sacrum.

Pregnancy-related lumbopelvic pain (nyeri pinggang dan pelvis pada kehamilan) merupakan istilah yang dipergunakan untuk menggambarkan permasalah musculoskeletal pada pinggang dan pelvis pada kehamilan. Kemudian dibagi menjadi dua terminology lagi yaitu pregnancy-relatel pelvic gridle pain (PPP) untuk menggambarkan nyeri terkait permasalahan musculoskeletal pada daerah pelvis dan pregnancy-related low back pain (PLBP) untuk menggambarkan nyeri daerah lumbal ${ }^{17}$.

Diagnosis nyeri pinggang dan pelvispada kehamilan dan diferensiasi antara PPP dan PLBP biasanya didasarkan pada gejala. PPP digambarkan sebagai nyeri yang dalam, menusuk, unilateral atau bilateral, berulang atau terus-menerus, timbul antara krista iliaka 
posterior dan lipatan gluteal, mungkin menjalar ke paha posterolateral, ke lutut dan betis, tetapi tidak ke kaki. PLBP selama kehamilan sangat mirip dengan nyeri lumbal yang dialami oleh wanita yang tidak hamil dan muncul sebagai rasa sakit di sekitar tulang belakang di area lumbal, di atas sacrum ${ }^{10}$. Pada penelitian ini menunjukkan $7.3 \%$ mengalami PPP dan 41.7\% mengalami PLBP. Prevalensi ini berbeda dengan beberapa penelitian lain yang menunjukkan PPP merupakan kondisi yang lebih sering dijumpai pada kehamilan ${ }^{13,16,7}$.

Diagnosis dan diferensiasi antara PLBP dan PPP menjadi sangat penting dalam manajemen nyeri pinggang dan pelvis.Praktik umum dalam mengelola PLBP adalah berolahraga, termasuk yoga. Sedangkan manajemen dasar PPP secara umum adalah beristirahat dan menghindari olah raga dan kegiatan sehari-hari yang memperburuk gejala ${ }^{14}$. Sebanyak 50\% wanita yang menderita nyeri pinggang dan pelvis pada kehamilan akan mencari saran dari profesional kesehatan dan $70 \%$ dari mereka akan menerima beberapa jenis perawatan, termasuk yoga ${ }^{12}$. Hal ini menunjukkan bahwa wanita hamil yang mengikuti kelas yoga prenatal mungkin sebelumnya telah mendapatkan penapisan dan saran dari petugas kesehatan sehingga yang lebih banyak menghadiri kelas yoga prenatal adalah ibu hamil yang mengalami PLBP.

Hasil penelitian ini menunjukkan rerata intensitas nyeri pinggang dan pelvis pada kelompok ibu hamil yang melaksanakan yoga prenatal adalah 1.88 menggunakan numeric pain ratting scale yang termasuk nyeri intensitas ringan. Hasil ini lebih rendah dari hasil penelitian lain yang menilai intensitas nyeri pinggang dan pelvis pada kehamilan secara umum $^{16,19,7}$. Sebuah review mendapatkan bahwa yoga prenatal memberikan banyak manfaat salah satunya adalah mencegah dan menurunkan intensitas nyeri pinggang dan pelvis pada kehamilan. Lebih lanjut penelitian ini menunjukkan bahwa yoga prenatal secara teratur 2 kali seminggu efektif mengurangi nyeri pinggang dan pelvis pada kehamilan ${ }^{5}$. Hasil ini menunjukkan bahwa pelaksanaan yoga prenatal di Kota Denpasar menurunkan intensitas nyeri pinggang dan pelvis yang dirasakan oleh ibu hamil terutama pada akhir kehamilan.

\section{Kesimpulan}

Intensitas nyeri pinggang dan pelvis pada ibu hamil trimester III di Kota Denpasar yang melaksanakan yoga prenatal tergolong nyeri intensitas ringan.

\section{Daftar Pustaka}

1. Carvalho, Maria Emília Coelho Costa, Luciana Cavalcanti Lima, Cristovam Alves de Lira Terceiro, Deyvid Ravy Lacerda Pinto, Marcelo Neves Silva, Gustavo Araújo Cozer, and Tania Cursino de Menezes Couceiro. 2017. "Low Back Pain during Pregnancy." Brazilian Journal of Anesthesiology 67(3):266-70.

2. Charpentier, K., J. Leboucher, M. Lawani, H. Toumi, G. A. Dumas, and A. Pinti. 2012. "Back Pain during Pregnancy and Living Conditions - a Comparison between Beninese and Canadian Women." Annals of Physical and Rehabilitation Medicine 55(3):148-59.

3. Cramer, Holger, Jane Frawley, Amie Steel, Helen Hall, Jon Adams, Alex Broom, and David Sibbritt. 2015. "Characteristics of Women Who Practice Yoga in Different Locations during Pregnancy.” BMJ Open 5(8):1-7. 
4. Gutke, Annelie, Hans Christian Östgaard, and Birgitta Öberg. 2006. "Pelvic Girdle Pain and Lumbar Pain in Pregnancy: A Cohort Study of the Consequences in Terms of Health and Functioning." Spine 31(5).

5. Jiang, Qinxian, Zhengguo Wu, Li Zhou, Jenae Dunlop, and Peijie Chen. 2015. "Effects of Yoga Intervention during Pregnancy: A Review for Current Status." American Journal of Perinatology 32(6):503-14.

6. Katonis, P., A. Kampouroglou, A. Aggelopoulos, K. Kakavelakis, S. Lykoudis, A. Makrigiannakis, and K. Alpantaki. 2011. "Pregnancy-Related Low Back Pain Katonis." Hippokratia 15(3):205-10.

7. Kovacs, Francisco M., Emma Garcia, Ana Royuela, Lourdes González, and Víctor Abraira. 2012. "Prevalence and Factors Associated with Low Back Pain and Pelvic Girdle Pain during Pregnancy: A Multicenter Study Conducted in the Spanish National Health Service." Spine 37(17):1516-33.

8. Mafikasari, Apriliyanti and Ratih Indah Kartikasari. 2015. "Posisi Tidur Dengan Kejadian Back Pain (Nyeri Punggung) Pada Ibu Hamil Trimester III." Surya 07:26-34.

9. Mohseni-Bandpei, Mohammad A., Moulod Fakhri, Marjan Ahmad-Shirvani, Masumeh Bagheri-Nessami, Ali Reza Khalilian, Masoud Shayesteh-Azar, and Hakimeh MohseniBandpei. 2009. "Low Back Pain in 1,100 Iranian Pregnant Women: Prevalence and Risk Factors." Spine Journal 9(10):795-801.

10. Noren L, Östgaard S, Nielsen TF, and Östgaard HC. 1997. "Reduction of Sick Leave for Lumbar Back and Posterior Pelvic Pain in Pregnancy." Spine 22(18):2157-60.

11. Pennick, Victoria and Sarah D. Liddle. 2013. "Interventions for Preventing and Treating Pelvic and Back Pain in Pregnancy." Cochrane Database of Systematic Reviews 2013(8).

12. Perkins, Jan, Roger L. Hammer, and Peter V. Loubert. 1998. "Identification and Management of Pregnancy-Related Low Back Pain." Journal of Nurse-Midwifery 43(5):331-40.

13. Pierce, Heather, Caroline S. E. Homer, Hannah G. Dahlen, and Jenny King. 2012. "Pregnancy-Related Lumbopelvic Pain: Listening to Australian Women." Nursing Research and Practice 2012:1-10.

14. Sabino, Jennifer and Jonathan N. Grauer. 2008. "Pregnancy and Low Back Pain." Current Reviews in Musculoskeletal Medicine 1(2):137-41.

15. Sari, Alfie Ardiana and Dian Puspitasari. 2016. "Hubungan Senam Yoga Dengan Kesiapan Fisik Dan Psikologis Ibu Hamil Dalam Menghadapi Persalinan Di Kelas Antepartum Gentle Yoga Yogyakarta.” Terpadu Ilmu Kesehatan 5(2):207-11.

16. Vermani, Era, Rajnish Mittal, and Andrew Weeks. 2010. "Pelvic Girdle Pain and Low Back Pain in Pregnancy: A Review." Pain Practice 10(1):60-71.

17. Wu, W. H., O. G. Meijer, K. Uegaki, J. M. A. Mens, J. H. Van Dieën, P. I. J. M. Wuisman, and H. C. Östgaard. 2004. "Pregnancy-Related Pelvic Girdle Pain (PPP), I: Terminology, Clinical Presentation, and Prevalence." European Spine Journal 13(7):575-89. 